\title{
FAMILIAL OCCURRENCE OF OSTEOCHONDRITIS DISSECANS
}

\author{
J. StougaArd, Aalborg, Denmark \\ From Sjukstugan, Jokkmokk, Sweden
}

Osteochondritis dissecans affecting several joints in one patient or several members of the same family is not unusual (Smith 1960, Stougaard 1961). This report is of another affected family. The first generation comprised the now deceased grandparents, the second generation two deceased and five living members, and the third generation one deceased and thirty living members. Of these forty people, thirty-one have been examined and radiographed. Three have answered questions by letter and have been radiographed. One living member of the family has not been traced.

First generation-The man (I 1 in Figure 1) was said to have had no joint trouble. His wife (I 2) suffered from swelling and pain in the elbows and knees from childhood onwards, with loss of movement.

Second and third generations-The eldest (II 1) and her five children (III 1 to 5) were normal, as was the second eldest (II 2). The third (II 3), a woman of seventy-six, had symptoms in the right elbow, and the radiographs showed flattening of the capitulum of the humerus, broadening of the head of the radius and exostoses consistent with old osteochondritis dissecans. Her three children (III 6 to 8 ) did not show signs of the disease. The fourth of the second generation (II 4), a man of seventy-four, had had pain and locking in both elbows and knees from boyhood onwards. The radiographs showed changes consistent with old osteochondritis dissecans. Of his five children, two (III 9 and 13), aged thirty-nine and nineteen respectively, were normal.

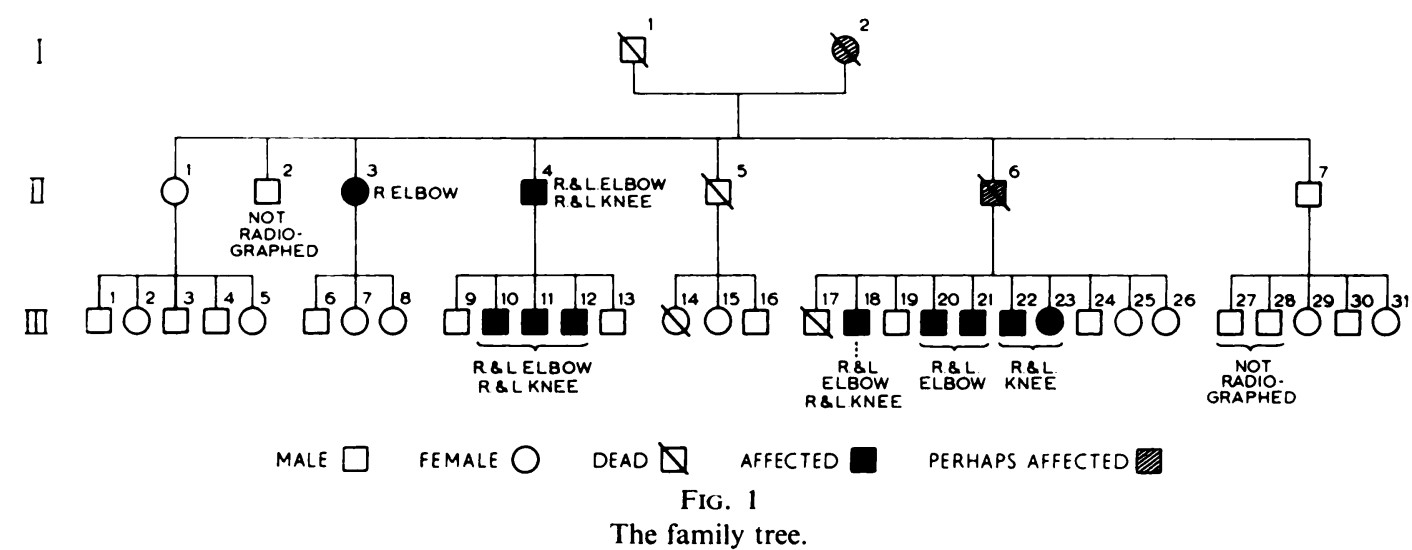

The other three (III 10 to 12), aged thirty-five, thirty-two and twenty-eight respectively, had each had trouble with both elbows and knees from childhood onwards. The radiographs showed osteochondritis dissecans in the capituli, and, in the knees, there was a defect in each medial condyle of the femora, with loose bodies and, in one, considerable incongruity. The fifth child in the second generation (II 5) and his three children (III 14 to 16) were normal. The sixth of the second generation (II 6) died at the age of sixty-two. He had had locking of the knees from the age of twelve and trouble with one elbow. He had ten children, the eldest of whom (III 17) died as an adult, having shown no signs of joint disease. The next (III 18), a man of thirty-four, had had pains in both elbows and locking of the knees, and five years previously a loose body had been removed from the left knee; his radiographs showed osteochondritis dissecans and osteoarthritis in all four joints. The third, fourth and fifth 
children (III 19 to 21) had had no joint trouble, but radiographs of the elbows of III 20 and 21 showed typical osteochondritis dissecans of the capituli. The sixth child (III 22), a man of twenty-five, had had locking in his knees since the age of twelve. At operation a year previously an osteochondritic defect in the medial condyle of the left femur was seen and a loose body was removed. Radiographs of the right knee showed similar changes. The seventh child (III 23), a girl of twenty-three, had had locking in both knees for years, and the radiographs showed the disease. The youngest three children (III 24 to 26 ) had neither symptoms nor signs of osteochondritis dissecans. The youngest of the second generation (II 7), a man of sixty-one, and his five children (III 27 to 31 ) were normal.

Fourth generation-Five members of the fourth generation have been examined. In one the radiographs of the left knee showed a large loose body only. The other four were under the age of ten.

The family as a whole had two different types of stature, short and tall. The first were from 153 to 164 centimetres ( 62 to 66 inches) tall and the second from 170 to 182 centimetres (67 to 72 inches). Osteochondritis dissecans of the knee joint was seen in the first group only. but it occurred in the elbows in both groups.

There were no consanguineous marriages, and none of those who married into the family had shown any symptoms or signs of the disease.

\section{SUMMARY}

1. A family, in which ten members of the second and third generations had osteochondritis dissecans, is described.

2. It is probable that the disease also occurred in the first and fourth generations.

\section{REFERENCES}

Sмinн, A. D. (1960): Osteochondritis of the Knee Joint. Journal of Bone and Joint Surgery, 42-A, 289.

StougaArd, J. (1961): The Hereditary Factor in Osteochondritis Dissecans. Journa! of Bone and Joint Surgery, 43-B, 256. 